\title{
From Applied Entomology to Evolutionary Ecology and Back
}

\author{
Ted C. J. Turlings
}

Published online: 12 March 2014

(C) Springer Science+Business Media New York 2014

"He is lost for science." Those were the words from a highly respected evolutionary ecologist when he learned, almost 30 years ago, that I would travel to the US to conduct a $\mathrm{PhD}$ project in chemical ecology at the USDA in Gainesville, Florida. Agro-ecosystems were commonly avoided like the plague by respected or respectable ecologists. An obsession with the $F$-word can be blamed for this. The general perception has long been that fundamental research is far more worthy than applied research, and that this can only be conducted in "natural" systems. This seems a bit silly if we consider that more than $50 \%$ of the terrestrial surface of our planet is being exploited and modified in some way or another by humans (http://data.worldbank.org), and it is time to accept that most of the relevant contemporary evolution is taking place in these exploited areas.

We also can wonder if it really is so bad to devote our research efforts to "unnatural" systems in order to address questions of importance to our society. Even the respected ecologist that criticized my career move eventually sold out and switched to applied research, initially most likely because of funding opportunities, but also perhaps because fundamental research was more and more considered to be compatible with trendy societal issues like climate change, invasive organisms, and biodiversity. What does this have to do with the Journal of Chemical Ecology and its 40th anniversary? It is my impression that the Journal and the scientists that contribute to it have made an important trendsetting contribution to what is considered to be important research. When I left Holland for my adventure in Florida, I entered the world of chemical ecology and applied entomology. I joined the group of Jim Tumlinson, one of about a dozen scientists that have paved the way for the field of chemical ecology and its journal. Their work on insect pheromones was groundbreaking and led to the very successful application of pheromones in insect pest control. Much of their work was published in the Journal of Chemical Ecology (JCE), but it also led to papers in journals with a slightly higher impact, like Nature and Science. Chemical ecology also was one of the first disciplines that was highly interdisciplinary, combining behavioral ecology, insect physiology, as well as analytical and synthetic chemistry. This extent of interdisciplinarity was a rarity at the time. In those early days, this very young discipline received considerable respect and attracted an important base of enthusiastic young scientists, also those that had a background in ecology and evolutionary biology. I argue that this new infusion caused a shift in the general focus of research in chemical ecology. It became more and more evident that not only pheromones, but also plant-derived chemicals are of utmost importance for the foraging behavior and performance of insects. Plants and the evolutionary processes that determined their interactions with insects started to dominate the field. This notion finds support in the types of papers that appeared in JCE. Consulting the Web-of-Science teaches us that indeed pheromone research largely dominated the earlier days of the field. The number of papers on pheromones has not decreased over the years, but other

T. C. J. Turlings $(\square)$

Institute of Biology, University of Neuchâtel, Neuchâtel, Switzerland e-mail: ted.turlings@unine.ch

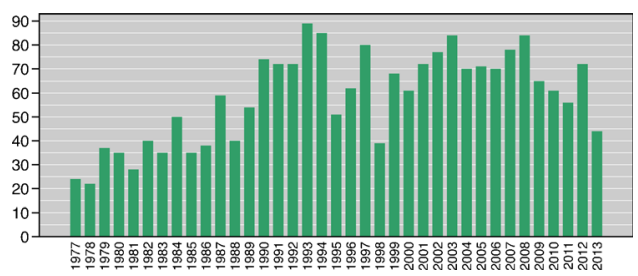

Fig. 1 Pheromones 1977 to 2013

topics have been introduced (Fig. 1). One of those is evolutionary ecology. The term evolution rarely occurred in earlier work, but, as Fig. 2 shows us, was an important aspect of much of the work that was published in JCE in the nineties, and it is still going strong. It seems roughly correct to say that most of this evolutionary work was inspired by a general interest in the evolution of plantinsect interactions. With the involvement of molecular plant physiologists, the work has revealed a tremendously sophisticated network of plant defense responses to herbivory and pathogen infections. This knowledge has now opened the way to ... application, again with a great emphasis on controlling insect pests.

If you have read this article until here, it probably not only means that many of your friends and family regularly tell you to get a life, but also that you are probably genuinely interested in the field of chemical ecology. In short, chemical ecologists read the Journal of Chemical Ecology and this is the final point that I would like to make. These days we are playing the numbers games with our publications in order to impress our peers, superiors, and funding agencies. Impact is what counts, and this is not always to the benefit of our Journal, but it should be. There is a false perception that we are better off publishing in journals that are a few numbers higher in average impact. If your intention is to maximize your h-index, this is the wrong notion. I would argue that your colleagues are more likely to read and cite your papers if they are published in JCE than in journals with a considerably higher impact factor. For myself this is certainly true. I searched for the average number of citations of the twenty $J C E$ papers that I have been author on and found that it is $50 \%$ higher than for the average of my papers published in journals that have an impact factor between 3 and 9. I like to think that I was not entirely lost for science when I decided for a career in chemical ecology. You won't be either, especially if you publish in the Journal of Chemical Ecology.

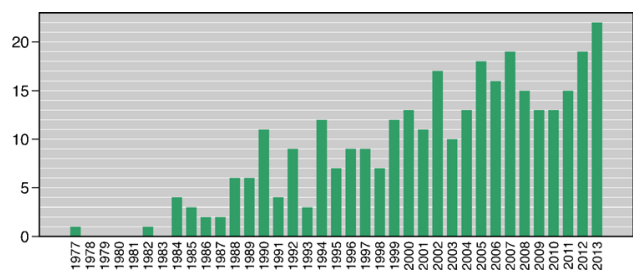

Fig. 2 Evolution 1977 to 2013 